\title{
HIPERMÍDIA EDUCACIONAL SOBRE PUNÇÃO VENOSA PERIFÉRICA: PERSPECTIVA DE ACADÊMICOS DE ENFERMAGEM*
}

Natasha Marques Frota', Lívia Moreira Barros², Amanda de Fátima Alves da Costa ${ }^{3}$, Zélia Maria de Sousa Araújo Santos ${ }^{4}$, Joselany Áfio Caetano ${ }^{5}$

'Enfermeira. Doutoranda em Enfermagem. Universidade Federal do Ceará. Fortaleza-CE-Brasil.

${ }^{2}$ Enfermeira. Mestranda em Enfermagem. Universidade Federal do Ceará. Fortaleza-CE-Brasil.

${ }^{3}$ Discente em Enfermagem. Universidade Federal do Ceará. Fortaleza-CE-Brasil.

${ }^{4}$ Enfermeira. Doutora em Saúde Coletiva. Universidade Federal Fortaleza.Fortaleza-CE-Brasil.

${ }^{5}$ Enfermeira. Doutora Enfermagem. Universidade Federal do Ceará. Fortaleza-CE-Brasil.

RESUMO: Estudo descritivo, com abordagem qualitativa, com objetivo de identificar a opinião de estudantes quanto à utilização de uma hipermídia educacional sobre Punção Venosa Periférica no ensino de enfermagem. Foram entrevistados 12 estudantes de enfermagem de uma universidade pública durante o primeiro semestre de 2013. As entrevistas permitiram a identificação dos núcleos de sentido e de categorização pela análise de conteúdo e originou quatro categorias: influência da hipermídia no aprendizado, tecnologia educacional como suporte ao ensino presencial, relação da hipermídia com a prática profissional e dificuldades de acesso. A hipermídia apresentou resultados positivos, pois a maioria dos acadêmicos relatou que o material ajudou na aprendizagem e gerou autonomia e interatividade no momento de estudar. Entretanto alguns referiram dificuldade de acesso a hipermídia relacionado principalmente ao servidor utilizado. Assim a hipermídia mostrou-se uma ferramenta válida para uso, uma vez que favoreceu o aprendizado e despertou o interesse e a curiosidade dos estudantes. DESCRITORES: Tecnologia da informação; Hipermídia; Enfermagem; Cateterismo periférico; Estudantes de enfermagem.

\section{EDUCATIONAL HYPERMEDIA ON PERIPHERAL VENIPUNCTURE: THE PERSPECTIVE OF STUDENTS OF NURSING}

\begin{abstract}
This descriptive qualitative study aimed to identify the opinion of students in relation to the use of educational hypermedia on Peripheral Venipuncture in the teaching of nursing. Interviews were held with 12 students of nursing from a public university, during the first semester of 2013. The interviews, through content analysis, allowed the identification of the nuclei of meaning and categorization, and gave rise to four categories: Influence of the hypermedia course on the learning, Educational technology as support for proximate teaching, Hypermedia's relationship with professional practice, and Difficulties in access. Hypermedia presented positive results, as the majority of the students reported that the material helped in the learning and led to autonomy and interactivity at the time of studying. However, some mentioned difficulty in accessing the hypermedia, mainly related to the server used. Thus, hypermedia was shown to be a valid tool for use, as it promoted learning and awoke the interest and curiosity of the students.
\end{abstract}

DESCRIPTORS: Information technology; Hypermedia; Nursing; Peripheral catheterization; Nursing students.

\section{HIPERMEDIA EDUCACIONAL SOBRE PUNCIÓN VENOSA PERIFÉRICA: PERSPECTIVA DE ACADÉMICOS DE ENFERMERÍA}

RESUMEN: Estudio descriptivo, con abordaje cualitativo, cuyo objetivo fue identificar la opinión de estudiantes acerca de la utilización de una hipermedia educacional sobre Punción Venosa Periférica en la enseñanza de enfermería. Fueron entrevistados 12 estudiantes de enfermería de una universidad pública durante el primer semestre de 2013. Las entrevistas posibilitaron la identificación de los núcleos de sentido y de categorización por el análisis de contenido y resultaron en cuatro categorías: influencia de la hipermedia en el aprendizado, tecnología educacional como soporte a la enseñanza presencial, relación de la hipermedia con la práctica profesional y dificultades de acceso. La hipermedia presentó resultados positivos, pues la mayoría de los académicos ha informado que el material ayudó en el aprendizaje y generó autonomía e interactividad en el momento de estudiar. Sin embargo, algunos apuntaron dificultad de acceso a hipermedia referente principalmente al servidor utilizado. Así, la hipermedia se mostró una herramienta válida para uso, una vez que ayudó en el aprendizaje y despertó el interés y la curiosidad de los estudiantes. DESCRIPTORES: Tecnología de la información; Hipermedia; Enfermería; Cateterismo periférico; Estudiantes de enfermería.

*Artigo extraído da Dissertação de Mestrado intitulada: Construção e validação de uma hipermídia educativa sobre punção venosa periférica. Universidade Federal do Ceará (UFC), 2013. 


\section{INTRODUÇÃO}

A utilização das Tecnologias da Informação e Comunicação (TICs) no campo educacional trouxe alterações significativas nas interações e na interatividade no processo de ensino e aprendizagem. Devido a esse fator, houve um grande aumento no número de cursos, tanto na modalidade presencial quanto a distância, que estão sendo mediados por Ambientes Virtuais de Aprendizagem (AVAs) ${ }^{(1)}$.

O AVA pode ser definido como um sistema computacional disponível na internet que é destinado ao suporte de atividades mediadas por tecnologias de informação e comunicação e permite o processo de ensino-aprendizagem por meio da mediação pedagógica entre os alunos e o professor. É capaz de integrar múltiplas mídias, linguagens e recursos e apresentar informações de maneira organizada, além de ampliar as interações entre os indivíduos e os objetos de conhecimento, propiciando a socialização de experiências e produções ${ }^{(2)}$.

Assim, essa revolução tecnológica produziu uma geração de alunos que estão desenvolvendo novos modos de perceber e aprender, uma vez que cresceram em ambientes de multimídias com expectativas e visão de mundo diferente de gerações anteriores. Nesta perspectiva, a inovação nos métodos de ensino e a criação de AVAs apresenta-se como desafios aos professores do mundo contemporâneo ${ }^{(3)}$.

Paralelamente a esse avanço, o ensino e as pesquisas na área de Enfermagem vem procurado adequar-se aos avanços da tecnologia na educação ${ }^{(2)}$. A partir do ano 2000, um crescente e importante avanço tem ocorrido no desenvolvimento da informática em enfermagem. Múltiplos temas têm sido abordados, relacionando o desenvolvimento de competências, a tomada de decisão, o impacto da internet e a multiplicidade de intervenções nos mais diferentes campos de atuação do enfermeiro ${ }^{(4)}$.

Novas estratégias de ensino e aprendizagem estão sendo inseridas no âmbito da enfermagem, entre elas, as metodologias que proporcionam ao aluno maior autonomia no aprendizado. Dentre os diversos recursos educacionais, destacamos a hipermídia educacional, que permite ao usuário receber as informações pelo computador e interpretá-las, possibilitando o processo de construção do conhecimento de forma agradável, eficaz e interativo ${ }^{(5-6)}$.
Porém, apesar dos avanços tecnológicos na área da enfermagem, ainda existem alguns procedimentos como a Punção Venosa Periférica (PVP), que causam ansiedade e insegurança aos alunos, o que alerta para a necessidade da criação de novas estratégias de ensino que deem subsídio para o aluno exercer suas atividades práticas com êxito e segurança, tendo em vista que a PVP é um procedimento rotineiramente realizado nas atividades práticas da equipe de enfermagem.

Frente a este contexto, a utilização de hipermídias intermediada pelo AVA, proporciona um complemento na formação do aluno para realizar determinados procedimentos de forma segura, pois aproximam o aluno da realidade. Esse fato contribui na aquisição de conhecimento necessário para conseguir superar a insegurança na execução de procedimentos de enfermagem ${ }^{(7)}$.

Diante dessas considerações, justifica-se a realização do presente estudo devido ao aumento do uso da informática no ensino de enfermagem, aproximando o discente da realidade prática de sua área de atuação. Vale ressaltar que os resultados desse estudo poderão contribuir com o aprimoramento das ferramentas e tecnologias existentes na área da enfermagem, tendo em vista que a opinião dos alunos sobre o uso de uma hipermídia e as dificuldades vivenciadas no AVA permite o ajuste de lacunas presente no ensino, assim como a avaliação do ensino por intermédio da Educação à distância (EaD).

Destarte o objetivo deste estudo foi identificar a opinião de estudantes quanto à utilização de uma hipermídia educacional sobre PVP no ensino de enfermagem.

\section{MÉTODO}

Estudo descritivo, com abordagem qualitativa, desenvolvido durante o primeiro semestre de 2013, na Universidade Federal do Ceará (UFC), com os alunos do curso de graduação em enfermagem do sexto semestre.

O presente estudo utilizou uma hipermídia educativa na modalidade de um curso EaD para os estudantes de enfermagem da disciplina de Enfermagem no Processo do Cuidar do Adulto II, como atividade complementar, voluntária, com carga horária de 16 horas/semanais.

A hipermídia encontra-se disponível na 
Plataforma Solar da UFC disponível no endereço http://solarpresencial.virtual.ufc.br/. A escolha do AVA Solar como apoio para a hipermídia ocorreu devido a sua apresentação open source e também pelo fato da UFC utilizar esse ambiente como apoio ao ensino presencial em diversas áreas de ensino.

Para que o aluno tenha acesso ao curso, foi necessário fazer um cadastro no AVA com nome de usuário e senha disponibilizada para realização do login. O acesso ao ambiente foi possível após aprovação do tutor/professor, a partir da solicitação de matrícula pelo usuário.

Na página inicial da hipermídia o aluno teve acesso às aulas, organizadas em seis módulos, que estão subdivididos em tópicos, sendo eles: Módulo 1: Introdução à punção venosa periférica; Módulo 2: Anatomia da rede venosa; Módulo 3: Procedimento de punção venosa periférica; Módulo 4: Complicações locais e sistêmicas da PVP; Módulo 5: Punção venosa periférica em pacientes especiais; e Módulo 6: Ações de não conformidade da PVP.

No decorrer das aulas há diferentes ferramentas, o que possibilita a interação entre os alunos, na hipermídia de PVP utilizou-se vídeos, fotografias, hipertextos, hiperlinks e exercícios. Essa diversidade possibilita ainda que essas ferramentas se tornem atrativas à medida que vão sendo utilizadas pelos alunos.

Com o intuito de identificar a opinião dos estudantes sobre o uso da hipermídia, foram utilizados alguns critérios de inclusão, sendo estes: estar regularmente matriculado na disciplina de Enfermagem no Processo do Cuidar do Adulto II, ter noções básicas de informática (tais como: ligar e desligar o computador, navegar na Internet, utilizar as ferramentas para imprimir, editar textos), apresentar disponibilidade para utilizar a hipermídia educativa por meio do ambiente virtual e se comprometer em concluir o curso no prazo de duas semanas, tempo necessário para conclusão e avaliação da hipermídia. Os critérios de exclusão foram: alunos que realizaram cursos sobre PVP anteriormente e que não concluíram a avaliação da hipermídia em tempo hábil.

Os participantes do estudo foram 12 acadêmicos de enfermagem, sendo esse número condicionado ao critério de saturação dos achados, que ocorre quando as informações tornam-se repetidas ou o acréscimo de novos dados for mínimo para submeterem-se aos procedimentos de análise ${ }^{(8)}$.

A coleta dos dados foi realizada em sala privativa, na própria universidade, conforme disponibilidade dos participantes e em horários alternativos às aulas para que não houvesse interrupção da participação dos alunos nas suas atividades curriculares. Para alcançar o objetivo do estudo, utilizou-se a entrevista semiestruturada como técnica de coleta de dados em que foram abordadas questões temáticas como a utilização das tecnologias educacionais para o ensino em enfermagem, o acesso a materiais didáticos digitais, bem como as principais limitações encontradas neste tipo de modalidade de ensino. As entrevistas foram gravadas, conforme a autorização dos estudantes, e tiveram a duração entre 20 a 60 minutos, sendo transcritas na íntegra.

Após a entrevista de 12 dos 29 potenciais participantes, observamos a ausência de novas informações e nos certificamos que houve saturação dos dados, levando-nos a finalizar a coleta de dados. Para preservar o anonimato, os estudantes foram identificados pela palavra Estudante, seguida de um número que representava a ordem de ingresso no estudo.

A análise dos dados empíricos foi realizada por três pesquisadores e ocorreu nas seguintes etapas: pré-análise; exploração do material; tratamento dos resultados e interpretação, segundo orientações para análise de conteúdo ${ }^{(8)}$.

Em obediência à Resolução 466/12, do Conselho Nacional de Saúde, o projeto foi submetido e aprovado pelo Comitê de Ética e Pesquisa da UFC com protocolo $n^{\circ} 215 / 11$. Os estudantes assinaram o Termo de Consentimento Livre e Esclarecido e o sigilo sobre as informações prestadas, a omissão de suas identidades lhes foram garantidos ${ }^{(9)}$.

\section{RESULTADOS}

Participaram deste estudo 12 acadêmicos de enfermagem, predominantemente do sexo feminino (11 mulheres e um homem) e na faixa etária de 22 a 26 anos. Todos relataram ter fácil acesso à Internet em casa, na universidade por meio de rede sem fio, na sala de informática, na biblioteca e nos grupos de pesquisa.

Além disso, todos os alunos possuíam também 
acesso à Internet pelo celular e relataram que esta servia de suporte no desempenho de suas atividades da graduação, pois os mesmos preferem a Internet a manuais e livros para tirar dúvidas e estudar para conteúdos das disciplinas do curso.

A partir desse cenário, o processo de análise dos dados permitiu a identificação de quatro categorias: influência da hipermídia no aprendizado; tecnologia educacional como suporte ao ensino presencial; relação da hipermídia com a prática profissional; e dificuldades de acesso.

\section{Influência da hipermídia no aprendizado}

A troca de informações entre acadêmicos através das ferramentas existentes na hipermídia como fóruns e chats permite a interatividade entre os alunos e o tutor bem como o compartilhamento de dúvidas e o feedback do conhecimento apreendido. É possível perceber essa influência através das seguintes falas:

Aprendi sobre o material utilizado no procedimento; quando se utilizar scalp ou abocath, além das indicações para a punção [...]. (Estudante 2)

$A$ anatomia [em relação às melhores veias]. As vantagens e desvantagens de cada instrumento. Os tipos de complicações que uma punção incorreta pode causar [...]. (Estudante 9)

O conhecimento a respeito das diferentes possibilidades da técnica, anatomia da rede vascular e das possíveis complicações de uma punção venosa incorreta [...]. (Estudante 11)

Conhecer melhor as veias e suas localizações, rever a técnica e a teoria [...]. (Estudante 6)

Neste sentido, a hipermídia mostrou-se favorável à aquisição de conhecimento, uma vez que os sujeitos do estudo afirmaram que o uso do AVA proporcionou um aprimoramento do saber sobre PVP como a anatomia da rede venosa, os materiais utilizados e os cuidados de enfermagem, permitindo, assim, a associação entre a teoria e a prática.

\section{Tecnologia educacional como suporte ao ensino presencial}

O uso de tecnologias no ensino pode servir de subsídio para uma formação que vai além da sala de aula, possibilitando ao aluno que ele escolha o momento ideal para a aprendizagem. Além disso, na hipermídia, o aluno tem acesso às diversas mídias interativas que facilitam a aquisição de conhecimento devido às inúmeras possibilidades de aprender. As falas abaixo retratam esta interação:

O que mais me atraiu a utilizar a hipermídia foi a facilidade de ter as aulas e a assisti-las fora do ambiente acadêmico, no momento que eu estivesse disponível [...]. (Estudante2)

Algumas informações eu nunca tinha ouvido falar nem nas aulas de laboratório e nem nos estágios [...]. (Estudante 7)

A hipermídia pode ser observada como um ambiente flexível e agradável para os estudos, a qual é capaz de solucionar dúvidas e promover novos conhecimentos, contribuindo, como uma ferramenta de suporte ao conteúdo administrado em sala de aula.

\section{Contribuição da hipermídia na prática profissional}

A prática de punção venosa periférica é um dos procedimentos básicos de responsabilidade da equipe de enfermagem, o que exige do profissional o conhecimento técnico e científico sobre o tema. Pode-se perceber por meio dos discursos:

Achei o assunto de grande importância para um futuro profissional de enfermagem, além da forma que foi apresentada para nós [...]. (Estudante 4)

É uma ferramenta muito importante para nós acadêmicos, pois nossa universidade nos proporciona um diferencial de ensino que nos ajudará a ficar mais qualificado para o mercado de trabalho [...]. (Estudante 10)

Considero o assunto de extrema importância para prática profissional e pretendo me inscrever em outros cursos à distância [...].(Estudante 8) 
A hipermídia serve para auxiliar o estudante de enfermagem no desempenho de suas atividades no atendimento aos pacientes, no início da prática hospitalar, pois facilita o processo de ensino-aprendizagem dos discentes quanto à memorização da sequência da técnica, permitindo acesso a materiais didáticos e interativos no momento desejado e reduzindo dúvidas decorrentes das diferentes formas de realização de um mesmo procedimento. Além disso, durante a vida profissional as hipermídias são ferramentas de aprendizado contínuo, reciclando o conhecimento sobre a técnica, promovendo, assim, a educação continuada do profissional.

\section{Dificuldades de acesso ao ambiente virtual}

Neste estudo, alguns participantes relataram dificuldades no acesso a hipermídia relacionado principalmente ao servidor utilizado. Assim, percebe-se a necessidade de uma orientação aos acadêmicos para a facilitação do acesso à informação, de forma a permitir a utilização da ferramenta de forma mais eficiente pelos usuários.

Encontrei dificuldade em acessar as aulas usando o Google Chrome. Quando mudei o navegador consegui acessar a hipermídia com mais facilidade e rapidez [...]. (Estudante 1)

Não sabia que o navegador influenciava a navegação do sistema, deixando o acesso mais lento [...]. (Estudante 2)

Em alguns momentos tive dificuldade de acesso devido o sistema não reconhecer minha senha [...]. (Estudante 5)

Dependendo do servidor que é utilizado os vídeos demoram mais para serem carregados [...]. (Estudante 9)

Achei chato porque após o cadastro tem que aguardar a liberação do curso pelo tutor [...]. (Estudante 11)

Assim, faz-se necessário ter um cuidado especial para prevê as dificuldades do usuário ou do grupo em relação ao ambiente que será utilizado, a fácil navegação, acessibilidade e funcionalidade torna o aprendizado efetivo e compreensível minimizando, os possíveis obstáculos referentes ao uso do AVA.

\section{DISCUSSÃO}

Dentre os diferentes recursos disponíveis para utilização na educação em enfermagem, a tecnologia é um meio para melhora da prática do ensino e da assistência de enfermagem, requerendo análise crítica sobre o contexto no qual esta tecnologia vai ser inserida, expressando a intencionalidade educativa que permeia o seu uso ${ }^{(6)}$.

A expectativa dos acadêmicos em relação à inserção de tecnologias educacionais no aprendizado é a possibilidade de acesso à informação fora da universidade. As informações são completas, principalmente em relação à aplicação prática, com a disponibilização de vídeos detalhados para a execução do procedimento.

A educação na área de enfermagem deve abranger conhecimentos técnicos e científicos adequados para a realização de atividades como a PVP(10). O conhecimento sobre a realização das técnicas adequadas, a anatomia da rede venosa, os materiais a serem utilizados e suas especificidades são essenciais para que o procedimento seja realizado com sucesso.

A utilização da hipermídia permitiu a complementação do conteúdo teórico fornecido em sala de aula, disponibilizou aos alunos materiais adicionais ilustrativos acerca da PVP, com vídeos e atividades complementares. Isto possibilitou a junção entre o conhecimento e a experiência do professor no ambiente acadêmico e a utilização de um ambiente virtual rico em ferramentas para o aprofundamento das técnicas para realização do procedimento.

O ambiente virtual despertou o interesse dos alunos devido a facilidade de acesso ao conhecimento no AVA, além da disponibilidade do material no ambiente virtual e comunicação facilitada com o tutor da hipermídia. Foi possível perceber a necessidade do desenvolvimento de hipermídias semelhantes, abordando as mais variadas técnicas de enfermagem, com acesso livre e fácil de todos os profissionais acadêmicos para proporcionar a educação continuada destes.

A interação com outros alunos e com o tutor 
foi citada pelos alunos como uma vantagem do uso da hipermídia. Uma das potencialidades do uso dos AVAs é a interatividade como possibilidade de reflexão e troca na construção de conhecimentos a ser usada pelo mediador ${ }^{(10)}$.

No contexto da Educação à distância (EaD), o favorecimento da interação possibilita novas relações com o conhecimento, já que nos AVAs o aluno tem a oportunidade de realizar escolhas e essas podem ser mediadas pelo uso de suportes e recursos tecnológicos ${ }^{(1)}$. A construção coletiva do conhecimento, a partir dos princípios da aprendizagem cooperativa e, a visão de educador multiplicador, que procura passar a sua experiência e acompanhar o percurso dos seus colegas e alunos, desvenda em conjunto novos caminhos e possibilidades ${ }^{(11)}$.

As ferramentas Chat e Fórum podem ser caracterizadas como importantes canais de comunicação que permitem o debate entre os alunos de aspectos importantes presentes no conteúdo da hipermídia. Recomenda-se que a atuação do tutor junto ao fórum seja dialógica, para que os cursistas não percebam essa ferramenta, apenas como mais um local de entrega de tarefas, mas sim, um espaço de diálogo constante, de novas indagações, questionamentos, e de contribuições dos demais colegas para uma determinada questão ou fato ${ }^{(3)}$.

Um estudo realizado no Rio de Janeiro com enfermeiros da atenção básica, que utiliza o teleconsultorias online em um programa de educação permanente à distância, mostrou resultados positivos, uma vez que traduz a necessidade de inovação nos meios educativos para profissionais da saúde ${ }^{(9)}$.

Em outro estudo(12) desenvolvido com acadêmicos de enfermagem foi possível observar que os mesmos consideraram o vídeo da hipermídia utilizado na pesquisa como uma maneira de relevância para a prática clínica, demonstrando que a utilização desse tipo de recurso didático estimula o aprendizado e possui repercussões significativas na carreira profissional. As hipermídias proporcionam um ambiente de acesso mais rápido às informações em vários formatos e a oportunidade de liberdade de acesso ao conhecimento.

Com o advento da tecnologia no ensino e na prática da enfermagem, houve a necessidade de uma adequação nas práticas pedagógicas, que possibilitasse um movimento mais dialético da triangulação do professor, aluno e objeto, na perspectiva do educador como um facilitador do processo ensino-aprendizado ${ }^{(4)}$. Assim, as tecnologias devem ser utilizadas no processo de ensino-aprendizagem, pois promovem a formação interativa do conhecimento, além de permitir uma visão mais ampla do assunto, apresentando-se como uma alternativa individualizada para o aprendizado $^{(13)}$.

A EaD permite que o aluno se comporte de forma mais ativa, desenvolva a iniciativa, o compromisso, a responsabilidade em gerenciar suas atividades e prazos. A flexibilidade de horário é um fator que contribui para que essa competência se desenvolva. $\mathrm{O}$ aluno passa a refletir para solucionar problemas, é estimulado a pesquisar e esclarecer dúvidas (a troca acontece virtualmente e pode ser feita até mesmo com colegas, em fóruns) e esta convivência virtual torna-se enriquecedora quando existe a oportunidade de participar ativamente na troca de ideias e reflexões, além da oportunidade de realizar um feedback presencial com os demais colegas, afim de articular pontos inerentes ao conteúdo programático visto na graduação ${ }^{(14)}$.

Neste contexto, a hipermídia consiste em um ambiente de aprendizagem flexível e interativo, que proporciona ao aluno a oportunidade de explorar o conteúdo de acordo com suas necessidades a partir de múltiplas perspectivas ${ }^{(15)}$. Esta estratégia de aprendizagem coloca o aluno no centro do processo educativo, uma vez que Ihe confere autonomia para realizar suas atividades de acordo com sua disponibilidade. Essa autonomia proporcionada torna possível a individualidade dos acadêmicos, onde cada um pode direcionar o aprendizado para os pontos nos quais necessitam além de disponibilizar o acesso ao docente e demais alunos por meio das ferramentas oferecidas. Sendo esta uma afirmação na apresentação dos resultados após o uso da hipermídia.

A utilização de uma hipermídia contribui para esta nova forma de aprender, uma vez que utiliza uma metodologia por meio da qual o aluno estuda por ele mesmo, de acordo com a sua disponibilidade, aproveitando melhor os conteúdos teóricos e desencadeando um processo que repercutirá na sua vida profissional, que é o de aprender assumindo responsabilidades ${ }^{(10-11)}$. Desse modo, o aluno é o construtor do seu 
conhecimento a partir da reflexão e indagação de sua prática. Sua participação no processo de formação ocorre de modo ativo, criativo, crítico, num exercício contínuo em que seja capaz de realizar análise, interpretação e síntese do objeto a ser aprendido, tendo também o compromisso com a sua formação ${ }^{(11)}$.

Em um estudo realizado em São Paulo, com acadêmicos de enfermagem matriculados no primeiro semestre foi avaliada a importância da inserção de tecnologias educacionais no ensino para complementar a formação dos enfermeiros. Dos resultados destacaram-se alguns pontos favoráveis tais como: possibilidade de obter informações além da sala de aula, maior comunicação dos alunos entre si e destes com o professor e, a influência positiva da utilização deste recurso na prática profissional ${ }^{(16)}$.

Os achados do estudo indicam a necessidade de orientar os alunos sobre as propriedades do $t$ utilizado e de identificar as dificuldades antes que o processo de aprendizagem tenha início, a fim de prevenir possíveis problemas na visualização e salvamento do material digital no computador ${ }^{(12)}$.

As dificuldades apresentadas pelos estudantes da UFC assemelham-se aos encontrados em um estudo realizado na Universidade Federal do Rio Grande do Sul (UFRGS), que utilizaram objetos educacionais digitais constituídos por hipertexto, jogo educativo e de simulação, voltado para estudantes do quarto período da graduação em enfermagem. No referido estudo, os alunos relataram que o material não foi explorado da forma como eles gostariam, uma vez que referiram dificuldade na instalação do programa e acesso ao material ${ }^{(14)}$.

Destaca-se, então, que para o pleno sucesso da ferramenta, AVA deve proporcionar acesso adequado e contar com educadores e tutores motivados e atualizados. Entretanto, o acesso do aluno é fundamental, sendo imprescindível ser participativo e atuante, acessar os conteúdos, buscar materiais além dos textos propostos e contribuir com reflexões para discussão $\mathrm{O}^{(13,17)}$.

Por fim, infere-se que o aluno que faz uso do AVA é sujeito do processo de ensinoaprendizagem mediado por recursos tecnológicos e humanos, interagindo com o ambiente em que ele se encontra, com o professor, com o material didático e com os demais alunos, promovendo assim a aprendizagem. Além disso, desperta o interesse do aluno acerca do tema, proporcionado por um ambiente virtual especifico com ferramentas de aprendizado detalhado da prática. Contudo, como já se percebe que a construção do conhecimento não ocorre de forma autônoma, ela perpassa o campo das relações sociais, na qual o educando pode compartilhar suas experiências adquiridas com outros alunos, a partir de uma aprendizagem colaborativa $^{(1)}$.

O uso das tecnologias educacionais exige envolvimento, dedicação e preparo dos profissionais, na busca da melhoria da abordagem educacional, dos processos decisórios e da qualidade da assistência à saúde da população, nos mais variados contextos, a partir de uma estrutura informacional adequada. É essencial que o enfermeiro saiba avaliar criticamente o conhecimento produzido, a informação comunicada e como efetivamente poderá ser aplicada, seja na educação, na gestão ou na prestação do cuidado em enfermagem, pois a ciência é a base deste investimento ${ }^{(4)}$.

\section{CONSIDERAÇÕES FINAIS}

A enfermagem tem se destacado como uma profissão de importante proximidade com o paciente, neste sentido torna-se pertinente uma boa preparação do futuro profissional no contexto da graduação, a partir de suportes educacionais direcionados a uma assistência de enfermagem qualificada. A prática de punção venosa periférica é um dos procedimentos básicos de responsabilidade da equipe de enfermagem, o que exige do profissional o conhecimento técnico e científico sobre o tema.

Sob esta ótica, abordar a temática de PVP junto aos alunos de graduação por meio de um suporte tecnológico mostrou-se uma ferramenta válida, uma vez que foi possível identificar algumas particularidades e boa aceitação por parte dos acadêmicos de enfermagem. Assim, diante destes achados a hipermídia será acrescida na disciplina de Enfermagem no Processo do Cuidar II, como uma ferramenta complementar ao ensino presencial.

Observou-se nesse estudo que o próprio aluno reconheceu as exigências do mercado de trabalho e que para tornar-se um bom profissional é importante aproveitar todas as 
iniciativas oferecidas no curso de enfermagem, sendo a hipermídia educativa uma ferramenta que favoreceu o interesse e curiosidades dos estudantes.

Como limitações dessa pesquisa, destaca-se a escolha da entrevista semi-estruturada como única estratégia de coleta de dados, realizada em apenas um encontro. Sugere-se a realização de futuras pesquisas para a melhor compreensão do objeto em estudo, como a observação das atividades dos alunos em diversos cenários de prática (estágios e laboratórios), bem como o seu desempenho nas aulas expositivas.

\section{REFERÊNCIAS}

1. Fruet FSO, Bastos FPB. Interação mediada por computador: hipermídia educacional nas atividades de estudo a distância. Conjectura. 2010;15(2):81-98.

2. Grossi MGR, Moraes AL, Breseia AT. Interatividade em ambientes virtuais de aprendizagem no processo de ensino e aprendizagem na educação a distância. Arq Bras Educ. [Internet] 2013;1(1) [acesso em 21 jan 2014]. Disponível em: http://periodicos.pucminas. br/index.php/arquivobrasileiroeducacao/article/ view/5683/5543

3. Holanda VR, Pinheiro AKB, Pontes CM. Educational hypermedia for the teaching of sexually transmitted diseases: a quase-experimental study. Online Braz J Nurs. [Internet] 2013;(12 Suppl): [acesso em 21 jan 2014]. Disponível em: http://www.objnursing.uff.br/ index.php/nursing/article/view/4182/pdf

4. Tobase L, Guareschi APDF, Frias MAE, Prado C, Peres HHC. Recursos tecnológicos na educação em enfermagem. J. Health Inform. 2013;5(3):77-81.

5. Alavarce DC, Pierin AMG. Elaboração de uma hipermídia educacional para o ensino do procedimento de medida da pressão arterial. Rev. Esc. Enferm. USP.[Internet] 2011;45(4). [acesso em: 21 jan 2014]. Disponível em: http://dx.doi.org/10.1590/S008062342011000400021

6. Freitas VF, Teles LMR, Lima TM, Vieira NFCV, Barbosa RCM, Pinheiro AKB, et al. Exame físico no pré-natal: construção e validação de hipermídia educativa para a enfermagem. Acta Paul. Enferm. [Internet] 2012;25(4). [acesso em: 21 jan 2014]. Disponível em http://dx.doi. org/10.1590/S0103-21002012000400016

7. Frota NM, Barros LM, Araújo TM, Caldini LN, Nascimento JC, Caetano JA. Construção de uma tecnologia educacional para o ensino de enfermagem sobre punção venosa periférica. Rev. gauch. enferm. [Internet] 2013;34(2). [acesso em: 21 jan 2014]. Disponível em: http://seer.ufrgs.br/ index.php/RevistaGauchadeEnfermagem/article/ view/33258/26035

8. Bardin L. Análise de conteúdo. Lisboa: Edições Setenta; 2004.

9. Brasil. Conselho Nacional de Saúde. Resolução n. 466, de 12 de dezembro de 2012. Dispõe sobre diretrizes e normas regulamentadoras de pesquisas envolvendo seres humanos. Diário Oficial da República Federativa do Brasil, Brasília, [Internet] 12 dez 2012. [acesso 17 jan 2014]. Disponível em: http://conselho.saude.gov. br/resolucoes/2012/Reso466.pdf

10. Faria MGA, David HMSL, Acioli S. Consultorias online: uma nova perspectiva no trabalho da enfermagem. Cogitare enferm. [Internet] 2013;18(2). [acesso em: 21 jan 2014]. Disponível em: http://ojs.c3sl.ufpr.br/ojs/ index.php/cogitare/article/view/29697

11. Camacho ACLF. Abordagem necessária sobre design didático para disciplinas online na enfermagem: análise reflexiva. Rev enferm UFPE online. [Internet] 2014;8(1). [acesso em: 15 jan 2014]. Disponível em: http://www. revista.ufpe.br/revistaenfermagem/index.php/revista/ article/view/5558/pdf_4461

12. Cardoso AF, Moreli L, Braga FTMM, Vasques Cl, Santos CB, Carvalho EC. Effect of a video on developing skills in undergraduate nursing students for the management of totally implantable central venous access ports. Nurse edc. today. [Internet] 2012;32(1). [acesso em: 17 jan 2014]. Disponível em: http://www.ncbi.nlm.nih. gov/pubmed/22036273

13. Condessa MB, Machado VB, Belsito LA, Caetano Jr MA, Alves EA. Educação a distância em assuntos regulatórios: relato de experiência em capacitação. Rev enferm UFPE on line. [Internet] 2012;6(2). [acesso em: 17 jan 2014]. Disponível em:http://www.revista. ufpe.br/revistaenfermagem/index.php/revista/article/ viewFile/2230/pdf_811

14. Silva APSS, Cogo ALP. Aprendizagem de punção venosa com objeto educacional digital no Curso de Graduação em Enfermagem. Rev. gauch. enferm. [Internet]2007;28 (2). [acesso em: 22 jan 2014]. Disponível em: http://seer.ufrgs.br/index.php/ RevistaGauchadeEnfermagem/article/view/3162/1733

15. Tanakan RY, Catalan VM, Zemiack J, Pedro ENR, Cogo ALP, Silveira DT. Objeto educacional digital: avaliação da ferramenta para a prática de ensino em enfermagem. Acta Paul. Enferm. [Internet] 2010;23(5). [acesso em: 22 jan 2014]. Disponível em: http://dx.doi. org/10.1590/S0103-21002010000500003

16. Peres HHS, Meira KC, Leite MMJ. Ensino de didática em enfermagem mediado pelo computador: avaliação discente. Rev. Esc. Enferm. USP. [Internet] 2007;41(2). 
[acesso em: 22 jan 2014]. Disponível em: http://dx.doi. org/10.1590/S0080-62342007000200014

17. Bulu SR, Pedersen S. Supporting problem-solving performance in a hypermedia learning environment: The role of students' prior knowledge and metacognitive skills. Elsevier. 2012;28(2):1162-9. 